\title{
Pathologic Aspects of Stomach Cancer in 1988 Surgical Cases*
}

By

\author{
Masao Muto,** Susumu Majima, Koichi Yoshida \\ Katsumi Karube, Teiichi Teshima \\ and Iwao Yamaguchi \\ From the Department of Surgery, Tohoku University School of \\ Medicine, Sendai; Directors: Prof. Emeritus \\ M. Muto and Prof. T. Maki
}

(Received for publication, October 14, 1963)

\begin{abstract}
Reviewing a total of 1988 surgical cases experienced at the authors' department, the morphologic aspects of stomach cancer were elucidated from various view-points. The statistical analyses covered the gross as well as microscopic features of the primary and the extragastric lesions, and a special interest was taken in the relationship between the nature of the primary tumor and the incidence of extragastric extension. The P.C. classification, a new grading of the cancer progress, was introduced on the basis of the extent of peritoneal dissemination which was revealed to be of great significance as a route for generalization of stomach cancer.
\end{abstract}

The incidence of carcinoma of the stomach is much higher in Japan than in most foreign countries, as shown in a recent publication of Dr. M. Segi, ${ }^{1)}$ Chairman of the Department of Public Health, School of Medicine, Tohoku University. Although the reason for such a high incidence still remains obscure, much effort of Japanese clinicians has been concentrated on earlier diagnosis and better treatment of this disease.

The authors have been interested in the surgical treatment of stomach cancer because of the nature of the disease. In the last 20 years, approximately two thousand cases of carcinoma of the stomach were treated at the authors' department and each of the cases was provided with a detailed record on symptoms, laboratory data and findings on operation. All the surgical specimens were subjected to thorough pathologic studies, the data of which were also filed to the records. Furthermore, most of the patients were followed-up after surgery,

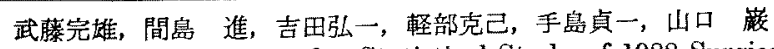

* The First Report of a Statistical Study of 1988 Surgical Cases of Stomach Cancer

** Present address, President, Fukushima Medical College, Fukushima, Japan 
mainly by correspondence and occasionally by interviews followed by clinical and laboratory examinations, to complete the records.

All the above efforts are to elucidate the factors which influence the postoperative prognosis of stomach cancer. Such an analysis of well examined surgical cases may be of great value to re-evaluate and improve the treatment of stomach cancer, since surgery is, at present, the only successful way for treating stomach cancer and, accordingly, surgeons are fully responsible for better treatment of this disease.

On the basis of these records, Muto ${ }^{2)}$ published a statistical report with special reference to the relation between the morphologic aspects of stomach cancer and the end-result of gastrectomy. Since a number of additional cases had been experienced since that time till March, 1961, when Dr. Muto retired from the Department of Surgery, Tohoku University School of Medicine, the data were revised, completed, and are presented in this report. The statistics cover pathology, symptomatology and the results of surgery. The first paper deals with the pathologic aspects of stomach cancer.

\section{MATERIALS}

A total of 2014 cases of stomach cancer were treated at the Department of Surgery (Prof. M. Muto), Tohoku University School of Medicine, during the 20 year period from April, 1941 to March, 1961 and 1988 among them were subjected to surgery. The statistics to be reported here are based on these 1988 patients. The type of surgery performed on these cases is shown in Table I. The stomach was resected in 1579 cases, while simple laparotomy or a palliative operation such as gastroenterostomy was performed on the remaining 409 cases.

Table I. Type of Operation Performed on 1988

Cases of Stomach Cancer

\begin{tabular}{c|cc}
\hline Operation & No. of cases & Per cent \\
\hline Resection & 1579 & 79.4 \\
Subtotal & 1259 & \\
Total & 260 & \\
Proximal & 60 & \\
\hline Non-resection & 409 & 20.6 \\
Anastomosis & 199 & \\
Simple laparotomy & 210 &
\end{tabular}

RESULTS

Gross Pathology of the Tumor

This chapter describes the gross pathology of stomach cancer as revealed by an examination of 1579 stomach specimens obtained by subtotal, proximal or total 
gastrectomy.

1. Size

Longitudinal and transverse diameters of the tumor were measured in the fresh, unfixed specimen and the size of the tumor was expressed by the product of the two diameters, in square centimeters. The frequency distribution of the tumor size in the 1579 specimens is shown in Table II. The size was $40 \mathrm{~cm}^{2}$ or larger in approximately 40 per cent of the total and the incidence of the minimal tumors measuring less than $10 \mathrm{~cm}^{2}$ was below 10 per cent.

TABLE II. Size of Tumor in 1579 Gastrectomized Cases

\begin{tabular}{c|cc}
\hline Size & No. of cases & Per cent \\
\hline Large $\left(40 \mathrm{~cm}^{2} \leq\right)$ & 647 & 41.0 \\
Medium $\left(20-40 \mathrm{~cm}^{2}\right)$ & 508 & 32.2 \\
Small $\left(10-20 \mathrm{~cm}^{2}\right)$ & 272 & 17.2 \\
Minimal $\left(<10 \mathrm{~cm}^{2}\right)$ & 152 & 9.6
\end{tabular}

\section{Extent of deep infiltration}

The extent of deep or vertical infiltration was determined by observing which layers of the stomach had been involved. The range of infiltration was first identified grossly by inspection of the cut surface of the tumor and then corrected by microscopy. As shown in Table III, the tumor involved the serosa in the majority of the cases. Those in which infiltration was limited to the submucosa without affecting the muscularis were less than 5 per cent of the total.

TABLE III. Extent of Deep Infiltration in 1579 Gastrectomized Cases

\begin{tabular}{l|cc}
\hline Deep infiltration & No. of cases & Per cent \\
\hline To submucosa & 73 & 4.6 \\
To muscularis & 282 & 17.9 \\
To serosa & 1224 & 77.5
\end{tabular}

3. Gross classification

Among the various gross classifications of carcinoma of the stomach, that of Borrmann ${ }^{3}$ is most popularly used in Japan. Borrmann's Type I is the circumscribed, polypoid or fungating tumor; Type II, the ulcerated tumor having elevated margin with sharp boundary; Type III, the ulcerated tumor whose boundary is partly sharp with definite elevation but partly obscure representing diffusive spread; and Type IV, the diffusively infiltrating carcinoma with no sharp edge demonstrable anywhere. 
TabLe IV. Gross Classification of the Tumors (Borrmann) in 1579 Gastrectomized Cases

\begin{tabular}{cc|cc}
\hline \multicolumn{2}{c|}{ Classification } & No. of cases & Per cent \\
\hline Type & I & 90 & 5.7 \\
& II & 799 & 50.6 \\
III & 507 & 32.1 \\
IV & 183 & 11.6
\end{tabular}

There are transitional features between the Types II, III and IV and these may be responsible for a wide variation in the incidence of those types in the literature. In Table IV is shown the classification in the present series.

4. Location

The authors divided the stomach into three transverse regions: the pyloric region (distal third), the body (middle third) and the cardiac region (proximal third). Each region was further divided into the anterior and posterior walls and the lesser and greater curvatures. Table $\mathrm{V}$ shows the frequency distribution of the location of the tumors in the present series. The tumor was situated in the pyloric region in more than half of the cases. It was also revealed that the lesser curvature was the most common site of carcinoma for each of the three regions.

TABLE V. Location of the Tumors in 1579 Gastrectomized Cases

\begin{tabular}{|c|c|c|c|c|c|}
\hline & $\begin{array}{c}\text { Lesser } \\
\text { curvature }\end{array}$ & $\begin{array}{l}\text { Greater } \\
\text { curvature }\end{array}$ & $\begin{array}{l}\text { Ant. or } \\
\text { post. wall }\end{array}$ & Annular* & Total \\
\hline Pyloric region & 446 & 175 & 70 & 143 & $\begin{array}{c}834 \\
(52.8 \%)\end{array}$ \\
\hline Body & 189 & 54 & 36 & 11 & $\begin{array}{c}290 \\
(18.4 \%)\end{array}$ \\
\hline $\begin{array}{l}\text { Pyloric region } \\
\text { and body }\end{array}$ & 131 & 36 & 20 & 33 & $\begin{array}{c}220 \\
(13.9 \%)\end{array}$ \\
\hline Cardiac region & 38 & 3 & 3 & 5 & $\begin{array}{c}49 \\
(3.1 \%)\end{array}$ \\
\hline $\begin{array}{l}\text { Body and cardiac } \\
\text { region }\end{array}$ & 68 & 3 & 7 & 9 & $\begin{array}{c}87 \\
(5.5 \%)\end{array}$ \\
\hline Entire stomach & & & & & $\begin{array}{c}99 \\
(6.3 \%)\end{array}$ \\
\hline
\end{tabular}

* Tumor involving both the curvatures and the anterior and posterior walls of the stomach to form an annular lesion.

\section{Histology of the Tumor}

Although all the stomach specimens of 1579 gastrectomized cases were subjected to histologic examinations, especially detailed studies using many 
sections were performed on 1347 cases which served as the objectives of the analysis of the end-results. This chapter is concerned with the histopathologic features of the tumors in these 1347 cases.

1. Histologic classification

The criteria described by Petersen and Colmers") have been used in the authors' department for the routine histologic classification of stomach cancer. In this classification, carcinoma adenomatosum (showing glandular structure) and carcinoma solidum (without glandular structure) are the two basic types, each of them being provided with a number of subtypes. When carcinoma adenomatosum and carcinoma solidum coexist in a tumor, the tumor is classified as the mixed type. The rare types, the fourth category, include such rare malignancies of the stomach as squamous cell carcinoma and carcinosarcoma.

Table VI demonstrates the histologic types of stomach cancer in the 1347 specimens of this series. The majority of the tumors were carcinoma adenomatosum or carcinoma solidum, the latter being a little more frequent. The only case of the rare type was adenocancroid developed in the antrum.

\begin{tabular}{c|c}
$\begin{array}{c}\text { TABLE VI. Histologic Classification of the Tumor (Petersen } \\
\text { and Colmers) in } 1347 \text { Gastrectomized Cases }\end{array}$ \\
\hline Classification & Incidence \\
\hline Carcinoma adenomatosum & $605(44.8 \%)$ \\
simplex & $369(27.4 \%)$ \\
papilliferum & $120(8.9 \%)$ \\
microcysticum & $52(3.9 \%)$ \\
gelatinosum & $64(4.6 \%)$ \\
Carcinoma solidum & $697(51.8 \%)$ \\
alveolare & $269(20.0 \%)$ \\
diffusum & $316(23.5 \%)$ \\
gelatinosum & $112(8.3 \%)$ \\
Mixed type & $44(3.3 \%)$ \\
Rare types & $1(0.1 \%)$
\end{tabular}

2. Broders' histologic grading of malignancy

Pure morphologic classifications such as that of Petersen-Colmers have little relation to the post-operative prognosis, as will be shown in the fourth paper of this series of study, and there have been attempts to establish a histologic grading of malignancy which represents, to some extent, the biological malignancy or the prognosis of the tumors. Among them, Broders' grading ${ }^{5,6)}$ is based on the quantitative relation between undifferentiated cells and differentiated cells of the malignant tissue and is popularly used in the United States of America.

Yamamura $^{7)}$ of the authors' department previously performed the Broders' grading on 833 cases of the present series, the result of which is cited in Table VII with statistics reported by American authors ${ }^{8,9)}$. In Table VIII is given the 
TABLE VII. Broders' Grading of Histological Malignancy of Stomach Cancer of Previous Authors

\begin{tabular}{|c|c|c|c|c|c|}
\hline \multirow{2}{*}{ Authors } & \multirow{2}{*}{$\begin{array}{c}\text { No. of } \\
\text { cases }\end{array}$} & \multicolumn{4}{|c|}{ Grades of malignancy } \\
\hline & & 1 & 2 & 3 & 4 \\
\hline Walters et al. $\left.{ }^{8}\right)$ & 805 & $29(3.6)$ & $190(23.6)$ & $316(39.3)$ & $270(33.5)$ \\
\hline Dochat \& Gray ${ }^{\prime \prime}$ & 1045 & $4(0.4)$ & $235(22.5)$ & $408(39.0)$ & $398(38.1)$ \\
\hline Yamamura? & 833 & $105(12.6)$ & $179(21.5)$ & $281(33.7)$ & $268(32.2)$ \\
\hline
\end{tabular}

Figures in parentheses indicate percentage.

TABLE VIII. Histological Malignancy of the Tumors in 1347 Gastrectomized Cases according to Broders' Grading

\begin{tabular}{c|c|cccc}
\hline \multirow{2}{*}{ Surgery } & \multirow{2}{*}{$\begin{array}{c}\text { No. of } \\
\text { cases }\end{array}$} & \multicolumn{4}{|c}{ Grades of malignancy } \\
\cline { 3 - 6 } & & 1 & 2 & 3 & 4 \\
\hline $\begin{array}{c}\text { Subtotal resection } \\
\begin{array}{c}\text { Proximal or } \\
\text { total resection }\end{array}\end{array}$ & 1073 & $127(11.9)$ & $230(21.4)$ & $347(32.2)$ & $369(34.4)$ \\
\hline Total & 274 & $12(4.4)$ & $32(11.7)$ & $87(31.7)$ & $143(52.2)$ \\
\hline & 1347 & $139(10.3)$ & $262(19.5)$ & $434(32.2)$ & $512(38.0)$
\end{tabular}

revised and completed statistics on 1347 cases, including Yamamura's cases, for the tumors resected by subtotal gastrectomy and for those obtained by total or proximal gastrectomy. Most statistics including that of the present series indicate that the grades 3 and 4 predominate in stomach cancer. It is also noted, in Table VIII, that the Broders' grade is generally higher in the tumors which required proximal or total gastrectomy than in those resected by conventional subtotal gastrectomy.

In Yamamura's series, the tendency was revealed between the extent of deep infiltration and the Broders' grade of malignancy that the more extended the former the higher the latter. The relations of Broders' grades to the prognosis of stomach cancer will be discussed in the fourth paper (in preparation).

3. CPL classification

The CPL classification of the neoplastic tissue proposed by Imai ${ }^{10)}$ is based on the pattern of malignant growth. This classification has been known to be a fairly good measure of the prognosis of carcinoma of any origin. The classification consists of two independent classifications, the CP and L classifications. The former is concerned with the pattern of the advancing front of the tumor, the interrelation between neoplastic tissue and reactive connective tissue being taken into consideration. When a tumor grows expansively without sprouting, or when the advancing margin of a tumor has sprouts which are all embodied in the newly formed connective tissue, the tumor is designated as $\mathrm{C}$ form (cirrhotic form). $\mathrm{P}$ form (progressive form) refers to such type of cancer growth that at least a por- 
tion of the advancing margin forms sprouts without reactive stromal proliferation, cancer cells or cell cords propagating in the tissue spaces. The grade of such progressive growth is expressed on a three-point scale, PI to P III. On the other hand the $\mathrm{L}$ classification deals with cancerous growth via lymphatic and blood vessels. $\mathrm{L}$ form (lymphatic and blood vessel permeation form) indicates that cancer cells or cell nests permeate and spread through the lymphatic or, less frequently, the blood vessels. The extent of such type of growth is graded as L I to $\mathrm{L} V$, while the lack of evidence of vessel permeation is designated $\mathrm{L} O$. Various combinations of the CP and L classifications are possible, e.g. C-L II or P III-L V.

Table IX shows the CPL classification in 1347 specimens of the present series. It was revealed that the classes representing less tendency of tumor advance, such as $\mathrm{C}, \mathrm{P} \mathrm{I}$ and $\mathrm{L} \mathrm{O}$, are less frequent in the proximal or total gastrectomy cases than in the subtotal gastrectomy cases. According to Mori11) who previously studied the relations of the CPL classification to other pathologic aspects of tumor, using a number of the present cases, larger $\mathrm{P}$ and $\mathrm{L}$ numbers were more commonly observed in the tumors of higher Broders' grades and in those showing deeper intramural infiltration than in the other cases. All of these facts suggest the significance of this classification as an indicator of the tendency toward tumor progress. The actual relationship between the CPL classification and the prognosis of stomach cancer will be presented later.

TaBle IX. CPL Classification of the Tumors in 1347 Gastrectomized Cases

\begin{tabular}{c|c|cccc}
\hline \multirow{2}{*}{ Surgery } & $\begin{array}{c}\text { No. of } \\
\text { cases }\end{array}$ & \multicolumn{5}{|c}{ CP classification } \\
\cline { 3 - 6 } & C & P I & P II & P III \\
\hline $\begin{array}{c}\text { Subtotal resection } \\
\begin{array}{c}\text { Proximal or } \\
\text { total resection }\end{array}\end{array}$ & $\begin{array}{r}1073 \\
274\end{array}$ & $338(31.5)$ & $289(26.9)$ & $308(28.7)$ & $138(12.9)$ \\
\hline Total & 1347 & $378(28.1)$ & $340(25.2)$ & $388(28.8)$ & $241(17.9)$ \\
\hline \multirow{2}{*}{ Surgery } & $\begin{array}{c}\text { No. of } \\
\text { cases }\end{array}$ & L O & L I & L II & L III-V \\
\hline $\begin{array}{c}\text { Subtotal resection } \\
\text { Proximal or } \\
\text { total resection }\end{array}$ & 1073 & $345(32.2)$ & $298(27.8)$ & $242(22.6)$ & $188(17.4)$ \\
\hline Total & 274 & $66(24.1)$ & $53(19.3)$ & $44(16.1)$ & $111(40.5)$ \\
\hline
\end{tabular}

\section{Intramural extension}

Carcinoma spreads in every direction, continuously by infiltration or discretely via the lymphatic and blood vessels. In stomach cancer, the extension is usually most remarkable in the submucosal and subserosal layers of the 
stomach and in these layers the microscopic range of infiltration not uncommonly exceeds the macroscopic limit of the tumor. This fact has attracted much interest of surgeons in relation to the problem of the transection line in gastrectomy.

The distance between the gross limit of the tumor and extent of histologic infiltration was studied, at the upper (oral) margin of the tumor, in 833 cases taken at random from the subtotal gastrectomy cases of this series. As shown in Table $\mathrm{X}$, the distance was $2 \mathrm{~cm}$ or longer in 149 cases or 18.0 per cent of the total, the maximum being $7.5 \mathrm{~cm}$.

\begin{tabular}{c|cc}
$\begin{array}{c}\text { Table X. Gross-Histologic Difference of the } \\
\text { Upper Tumor Margin in } 833 \\
\text { Gastrectomy Cases } \\
\text { Gubtotal }\end{array}$ \\
\hline Distance & Frequency & Per cent \\
\hline$<0.5 \mathrm{~cm}$ & 181 & 21.7 \\
$0.5 \mathrm{~cm}-1.0 \mathrm{~cm}$ & 262 & 31.4 \\
$1.0 \mathrm{~cm}-2.0 \mathrm{~cm}$ & 241 & 28.9 \\
$2.0 \mathrm{~cm}-3.0 \mathrm{~cm}$ & 93 & 11.2 \\
$3.0 \mathrm{~cm}-4.0 \mathrm{~cm}$ & 28 & 3.4 \\
$4.0 \mathrm{~cm}-5.0 \mathrm{~cm}$ & 21 & 2.6 \\
$5.0 \mathrm{~cm} \leq$ & 7 & 0.8
\end{tabular}

TABLE XI. Location of Most Advanced Infiltration toward Cardia in 833 Subtotal Gastrectomy Cases

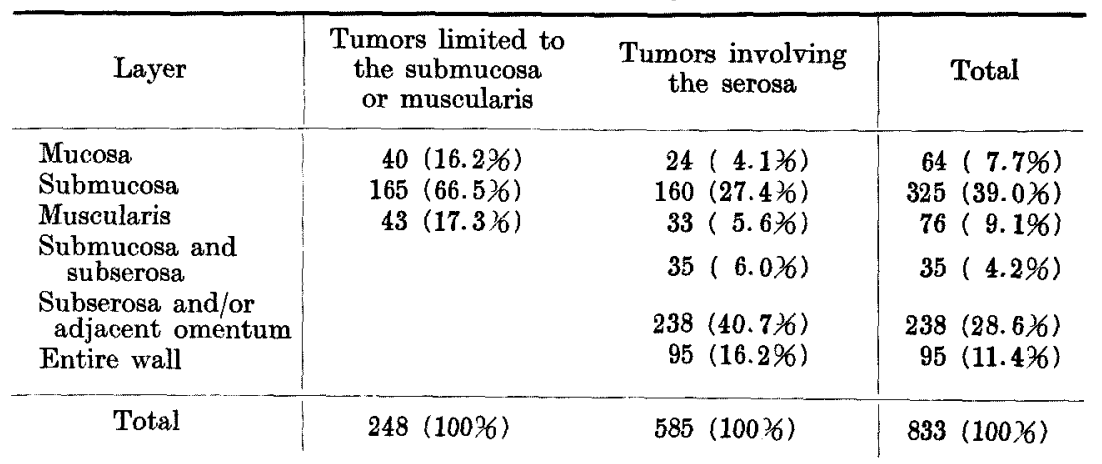

Table XI shows in which layer of the stomach wall cancerous infiltration toward the cardia was most advanced. The most advanced infiltration was located in the submucosa, or in the subserosa and/or adjoining omentum in the majority of the cases, as might be expected from the fact that these layers are rich in the lymphatic system, and much less frequent in the mucosa or muscularis. In Table XII is shown similar statistics in 149 tumors in which infiltration toward the cardia exceeded the upper gross limit of the tumor by $2 \mathrm{~cm}$ or more. It 
TABLE XII. Location of Most Advanced Infiltration toward Cardia which was $2 \mathrm{~cm}$ or more beyond the Upper Gross Limit of the Tumor

\begin{tabular}{|c|c|c|}
\hline Layer & Frequency & Per cent \\
\hline Mucosa & 5 & 3.4 \\
\hline Submucosa & 30 & 20.1 \\
\hline Muscularis & 2 & 1.3 \\
\hline $\begin{array}{l}\text { Submucosa and } \\
\text { subserosa }\end{array}$ & 6 & 4.0 \\
\hline $\begin{array}{l}\text { Subserosa and/or } \\
\text { adjacent omentum }\end{array}$ & 91 & 61.1 \\
\hline Entire wall & 15 & 10.1 \\
\hline Total & 149 & 100.0 \\
\hline
\end{tabular}

should be noted that the most advanced infiltration was in the subserosa or in the omentum in more than 60 per cent of such cases. Such a finding is clinically very important and the authors are of the opinion that this type of extension represents incipient carcinomatous peritonitis.

\section{Extragastric Spread}

This chapter shows the statistics on the extragastric spread of stomach cancer in terms of peritoneal dissemination, lymphatic metastasis and metastasis to the distant organs. Local extension of carcinoma to the esophagus, duodenum etc. will be discussed separately by Majima et al. ${ }^{12}$ )

1. Peritoneal dissemination

The term peritoneal dissemination has usually meant to indicate the metastasis to the serous membrane of the peritoneal cavity, including the omentum, mesentery, serosa of the intestine and parietal peritoneum, caused by implantation of the tumor cells. However, cancerous spread to the abdominal cavity can take place through various routes other than implantation. According to a histologic examination of the resected omentum by Sato ${ }^{13)}$ of the authors' department, there was evidence that more than half of "disseminated" cancer foci of the omentum had been formed by continuous propagation of carcinoma from the involved serosa of the stomach. The next most common route was the continuous spread of carcinoma through adhesion of the omentum to the infiltrated serosa covering the tumor. Besides, findings suggesting propagation via the lymph channel (Fig. 1) or the vein (Fig. 2) or peritoneal infiltration from the metastasized lymph nodes (Fig. 3) were obtained. Therefore, the peritoneal dissemination in this paper refers to any kind of metastasis to the serous membrane of the abdominal cavity, regardless of pathogenesis.

Incidence: The incidence of peritoneal dissemination revealed on operation of 1988 cases of stomach cancer is shown in Table XIII. It should be noted that 


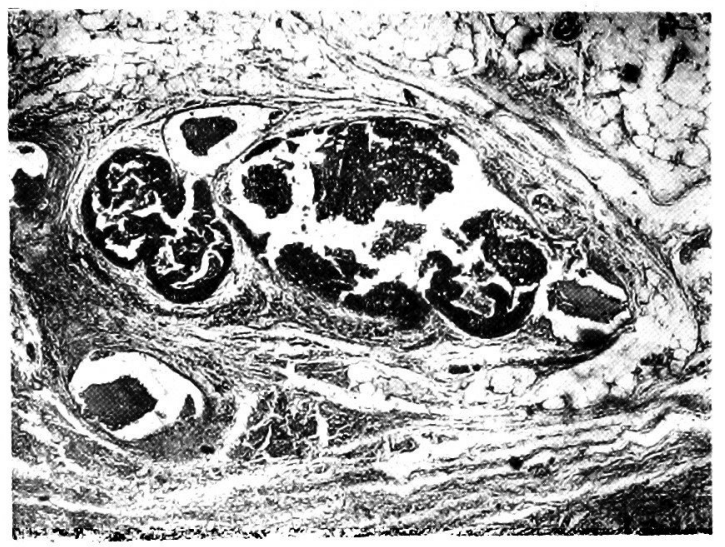

Fig. 1. Photomicrogram showing a cancer cell thrombus found in a lymph channel of the lesser omentum.

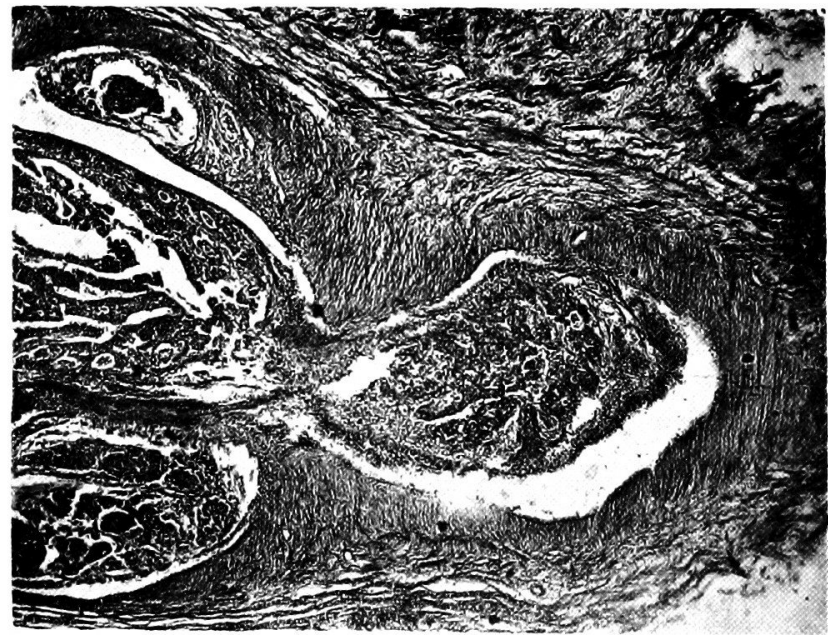

Fig. 2. Photomicrogram showing a cancer cell thrombus found in a venous vessel of the greater omentum.

the incidence was 100 per cent for cases in which stomach resection was impossible and as high as 79.3 per cent even for those subjected to conventional subtotal resection. The overall rate was 86.4 per cent.

Omental involvement: Among various types of peritoneal dissemination, omental dissemination is particularly important since it may be removed surgically, whereas no surgical treatment is indicated in generalized dissemination. The incidence of cancer dissemination to the greater and lesser omenta, based on histologic studies of 1035 stomach specimens (with the greater and lesser omenta excised en bloc), is shown in Table XIV. Those with omental involvement were 


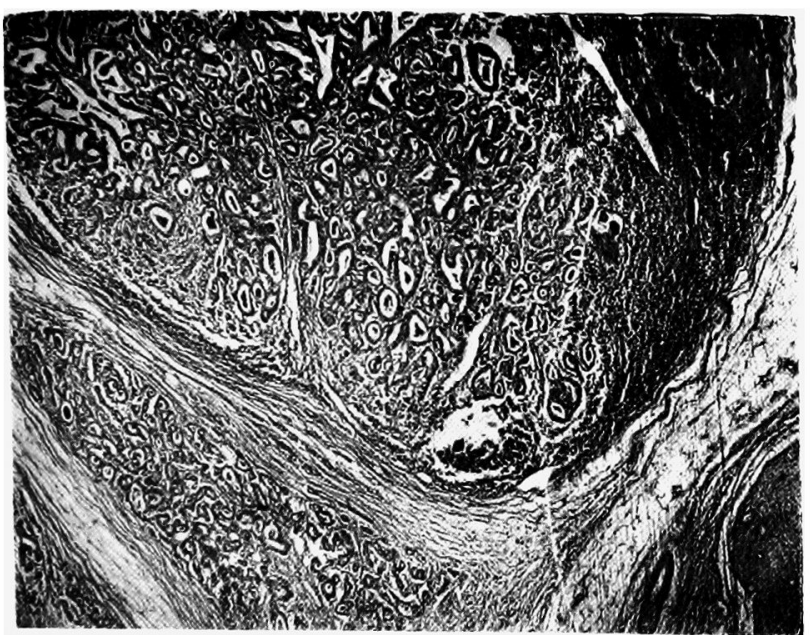

Fig. 3. Photomicrogram showing a metastasized lymph node of the omentum. Cancer cells invade the capsule of the node to spread into the omental tissue.

TABLE XIII. Peritoneal Dissemination of Stomach Cancer in 1988 Surgical Cases

\begin{tabular}{l|c|c|c}
\hline \multicolumn{1}{c|}{ Surgery } & $\begin{array}{c}\text { Total no. } \\
\text { of cases }\end{array}$ & $\begin{array}{c}\text { No. of positive } \\
\text { cases }\end{array}$ & Per cent \\
\hline Subtotal resection & 1259 & 998 & 79.3 \\
Proximal resection & 60 & 55 & 91.7 \\
Total resection & 260 & 255 & 98.1 \\
$\begin{array}{c}\text { Anastomosis or } \\
\text { simple laparotomy }\end{array}$ & 409 & 409 & 100.0 \\
\hline \multicolumn{1}{c}{ Total } & 1988 & 1717 & 86.4
\end{tabular}

Table XIV. Omental Dissemination of Stomach Cancer in 1035 Gastrectomized Cases

\begin{tabular}{c|c|ccc|c}
\hline \multirow{2}{*}{ Surgery } & \multirow{2}{*}{$\begin{array}{c}\text { No. of } \\
\text { cases }\end{array}$} & \multicolumn{4}{|c}{ Omental dissemination } \\
\cline { 3 - 7 } & $\begin{array}{c}\text { Lesser } \\
\text { omentum }\end{array}$ & $\begin{array}{c}\text { Greater } \\
\text { omentum }\end{array}$ & Both & Total \\
\hline $\begin{array}{c}\text { Subtotal resection } \\
\begin{array}{c}\text { Proximal or } \\
\text { total resection }\end{array}\end{array}$ & 833 & 184 & 78 & 383 & $645(77.4 \%)$ \\
\hline Total & 202 & 25 & 4 & 169 & $198(98.0 \%)$ \\
\hline & 1035 & 209 & 82 & 552 & $843(81.4 \%)$
\end{tabular}

as many as 98.0 per cent of proximal or total gastrectomy cases and 77.4 per cent of subtotal gastrectomy cases.

Concerning the relation of omental dissemination to pathologic aspects of the 
primary tumor, it was found that the incidence of dissemination became higher as deep infiltration of the tumor became more extensive. In fact, the incidence was 91.5 per cent for the tumors invading the subserosa or serosa, 34.7 per cent for those invading the muscularis and 6.9 per cent for those limited to the submucosa. It should be emphasized here, however, that approximately 7 per cent of the tumors whose deep infiltration was limited to the submucosa were associated with omental dissemination, representing lymphatic or hematogenous metastasis. Furthermore, omental dissemination was revealed in approximately 36 per cent of the cases in which no lymph node involvement was recognized. These facts exhibit a great clinical significance of omental dissemination, indicating that the omenta should be completely removed at surgery even when the primary tumor seems to be little advanced or even when there is no evidence of lymphatic metastasis.

P.C. classification (Muto): In relation to the clinical importance of peritoneal dissemination mentioned above, Muto established a new classification on the progress of stomach cancer, taking the extent of peritoneal dissemination as the measure. The classification is named P.C. classification.

P.C. is the abbreviation for peritonitis carcinomatosa which has been used, so far, to express such advanced peritoneal involvement as associating ascites. The usage of the term P.C. is based on the authors' idea that peritonitis carcinomatosa in the classic sense is not a sudden phenomenon but there should be a series of intermediate conditions, the earliest extreme of which is local infiltration of carcinoma to the serosa of the stomach.

The P.C. classification has a four-point scale, P.C. O to III. P.C. O means no evidence of peritoneal involvement. P.C. I represents the incipient stadium of peritoneal involvement in which dissemination or infiltration is limited to the serosa of the stomach or, at most, to the omentum very adjacent to the stomach. P.C. II is the intermediate stadium of dissemination, including omental involvement which can be removed by gastrectomy accompanied with complete excision of the omenta. Partial involvement of the serosa of the adjacent organs is also included to this grade provided the lesions can be removed by resection of these organs combined with gastrectomy. P.C. III designates such wide spread dissemination that cannot be controlled surgically. This condition may be equivalent to the classic peritonitis carcinomatosa. Thus, it may be understood that the P.C. grading is from the clinical view-point, in relation to the surgical indication.

Table XV shows the P.C. classification applied to 1347 resected cases of this series. For both the cases of subtotal gastrectomy and those demanding proximal or total gastrectomy, the majority were P.C. I or II. Six cases of P.C. III were those on which gastrectomy was performed for palliation. The frequency of P.C. III would be much higher when non-resected cases were included or when the statistics were based on autopsy cases. 
TABLE XV. P.C. Classification of Stomach Cancer in 1347 Gastrectomized Cases

\begin{tabular}{c|r|rrrr}
\hline Surgery & $\begin{array}{c}\text { No. of } \\
\text { cases }\end{array}$ & P.C. O & P.C. I & P.C. II. & P.C. III \\
\hline $\begin{array}{c}\text { Subtotal resection } \\
\begin{array}{c}\text { Proximal or } \\
\text { total resection }\end{array}\end{array}$ & 1073 & $245(22.8)$ & $558(52.0)$ & $268(25.0)$ & $2(0.2)$ \\
\hline Total & 1347 & $253(2.9)$ & $62(22.6)$ & $200(73.0)$ & $4(1.5)$ \\
\hline
\end{tabular}

The relation between the extent of deep infiltration of stomach cancer and the P.C. classification in these cases is shown in Table XVI, which indicates that peritoneal dissemination becomes more extensive, as a rule, as the infiltration to the stomach wall becomes deeper. Two of 66 cases whose deep infiltration was limited to the submucosa and 66 of 244 cases limited to the muscularis were judged to be P.C. I because of disseminated cancer foci on the omentum, though the serosa covering the primary tumor was histologically intact. In 11 of 1037 cases in which cancer infiltration had reached the subserosa, the surface of the serosa was not involved and dissemination was found nowhere in the abdominal cavity, leading to the grading of P.C. O.

TABLE XVI. Relation between Deep Infiltration of Stomach Cancer and Peritoneal Dissemination

\begin{tabular}{|c|c|c|c|c|}
\hline $\begin{array}{l}\text { Deep infiltration } \\
\text { P.C. }\end{array}$ & To submucosa & To muscularis & To subserosa & Total \\
\hline $\begin{array}{ll}\text { P.C. } & \text { O } \\
\text { P.C. } & \text { I } \\
\text { P.C. } & \text { II } \\
\text { P.C. } & \text { III }\end{array}$ & $\begin{array}{r}64 \\
2\end{array}$ & $\begin{array}{r}178 \\
66\end{array}$ & $\begin{array}{r}11 \\
552 \\
468 \\
6\end{array}$ & $\begin{array}{r}253 \\
620 \\
468 \\
6\end{array}$ \\
\hline Total & 66 & 244 & 1037 & 1347 \\
\hline
\end{tabular}

2. Lymph node metastasis

Incidence: Lymphatic metastasis is one of the most common routes for the extragastric spread of stomach cancer. In Japanese literature, the incidence of regional lymph node metastasis in gastrectomized cases ranges from 75 per cent to 87 per cent. The incidence in the present series, revealed by the histologic examination of 1347 stomach specimens, is as shown in Table XVII. The authors divided the regional lymph nodes of the stomach simply into two groups: the stomach nodes which are located adjacent to the stomach wall and the retroperitoneal nodes which exist along such vessels as the hepatic and splenic arteries and the trunk of the left gastric artery. Metastasis to the stomach nodes was designated L.M. I and that to the retroperitoneal nodes L.M. II. L.M. III indicates 
TABLE XVII. Regional Lymph Node Metastasis of Stomach Cancer in 1347 Gastrectomized Cases

\begin{tabular}{c|c|cc|c}
\hline \multirow{2}{*}{ Surgery } & \multirow{2}{*}{$\begin{array}{c}\text { No. of } \\
\text { cases }\end{array}$} & \multicolumn{4}{|c}{ Lymph node metastasis } \\
\cline { 3 - 5 } & & L.M. I & L.M. II-III* & Total \\
\hline $\begin{array}{c}\text { Subtotal resection } \\
\begin{array}{c}\text { Proximal or } \\
\text { total resection }\end{array}\end{array}$ & 1073 & $354(33.0)$ & $518(48.3)$ & $872(81.3)$ \\
\hline Totoal & 274 & $50(18.3)$ & $213(77.7)$ & $263(96.0)$ \\
\hline
\end{tabular}

* Cases of L.M. III subjected to palliative gastrectomy.

extensive lymphatic metastasis involving not only regional lymph nodes of the stomach but also farther nodes.

Thus, the frequency of lymph node metastasis of stomach cancer was estimated to be approximately 84 per cent when based on gastrectomized cases. The rate would be much higher when irresectable cases, all being associated with lymph node involvement, were taken into account.

Relation to the nature of primary tumor: Tables XVIII to XXI show the relations of lymph node metastasis to various morphologic aspects of the primary tumor in 1073 cases of stomach cancer resected by subtotal gastrectomy. Although the rate of metastasis was higher in larger tumors, it should be emphasized here that lymph node involvement was observed in more than half of the cases with very small tumors (Table XVIII). A close correlation was found between the extent of deep infiltration of carcinoma and the incidence of lymph node

TABLE XVIII. Relation between Size of the Tumor and Lymph Node Metastasis

\begin{tabular}{l|c|cc}
\hline Size* & $\begin{array}{c}\text { Total no. } \\
\text { of cases }\end{array}$ & $\begin{array}{c}\text { No. of cases } \\
\text { with metastasis }\end{array}$ & Per cent \\
\hline Large & 366 & 319 & 87.2 \\
Medium & 368 & 315 & 85.6 \\
Small & 207 & 162 & $\mathbf{7 8 . 3}$ \\
Minimal & 132 & 76 & 57.6
\end{tabular}

* Cf. Table II.

TABLE XIX. Relation between Deep Infiltration of the Tumor and Lymph Node Metastasis

\begin{tabular}{l|c|cc}
\hline Deep infiltration & $\begin{array}{c}\text { Total no. } \\
\text { of cases }\end{array}$ & $\begin{array}{c}\text { No. of cases } \\
\text { with metastasis }\end{array}$ & Per cent \\
\hline To submucosa & 64 & 15 & 23.4 \\
To muscularis & 237 & 146 & 61.6 \\
To serosa & 772 & 711 & 92.1
\end{tabular}


TABLE XX. Relation between Gross Appearance of the Tumor and Lymph Node Metastasis

\begin{tabular}{rr|c|cc}
\hline $\begin{array}{c}\text { Borrmann's } \\
\text { classification }\end{array}$ & $\begin{array}{c}\text { Total no. } \\
\text { of cases }\end{array}$ & $\begin{array}{c}\text { No. of cases } \\
\text { with metastasis }\end{array}$ & Per cent \\
\hline Type & I & 67 & 43 & 64.2 \\
II & 582 & 473 & 81.3 \\
III & 336 & 280 & 83.3 \\
IV & 88 & 76 & 86.4
\end{tabular}

TABLE XXI. Relation between Histology of the Tumor and Lymph Node Metastasis

\begin{tabular}{l|c|cc}
\hline $\begin{array}{c}\text { Petersen-Colmers } \\
\text { classification }\end{array}$ & $\begin{array}{c}\text { Total no. } \\
\text { of cases }\end{array}$ & $\begin{array}{c}\text { No. of cases } \\
\text { with metastasis }\end{array}$ & Per cent \\
\hline Ca. adenomatosum & 501 & 390 & 77.8 \\
Ca. solidum & 534 & 449 & 84.1 \\
Mixed type & 38 & 33 & 86.8
\end{tabular}

metastasis, in such a way that the deeper the former was the higher the latter became (Table XIX). However, even carcinomas whose vertical infiltrations were limited to the submucosa showed lymph node metastasis at an incidence of 23.4 per cent. On the other hand, the relations to the gross and histologic aspects of the tumor were rather insignificant (Tables XX and XXI).

It was also revealed that the lower grades of histological malignancy (Broders) as well as $\mathrm{C}$ or $\mathrm{L} \mathrm{O}$ of the CPL classification were associated with a little lower incidence of lymph node involvement. Although the correlation between the P.C. classification and the extent of lymph node metastasis was statistically significant (Table XXII), peritoneal dissemination without lymph node involvement or lymph node metastasis without peritoneal involvement was also observed in a considerable number of cases, suggesting that peritoneal dissemination and lymph node metastasis proceed not absolutely simultaneously.

TABLE XXII. Relation between Peritoneal Dissemination and Lymph Node Metastasis

\begin{tabular}{c|rrr|r}
\hline $\begin{array}{c}\text { Lymph node } \\
\text { metastasis }\end{array}$ & L.M. O & L.M. I & L.M. II & Total \\
$\begin{array}{c}\text { Peritoneal } \\
\text { dissemination }\end{array}$ & & & & \\
\hline P.C. 0 & 132 & 74 & 39 & 245 \\
P.C. I & 62 & 213 & 283 & 558 \\
P.C. II & 7 & 67 & 194 & 268 \\
P.C. III & 0 & 0 & 2 & 2 \\
\hline Total & 201 & 354 & 518 & 1073
\end{tabular}


3. Metastasis to remote organs

Remote metastasis of stomach cancer takes place in various organs such as the liver, ovarium, lung, adrenal, kidney, spleen, bone and skin. Among these, the liver and ovarial metastases are of practical importance since they may be encountered on operation, while metastases to other organs are less frequent and usually observed only at autopsy of advanced cases.

Regarding the remote metastasis of carcinoma, much attention has been concentrated on the problem of cancer cells in the circulating blood. The experience of the authors' department in this field was already published by Maki et al. ${ }^{14}$ ) and will not be mentioned here.

Liver metastasis: The liver is the most frequent target of hematogenous metastasis of stomach cancer. The incidence has been reported, in Japan, to be 5.4 to 8.9 per cent of the surgical cases and 29.8 to 60.0 per cent of the autopsy cases.

In the present series, the liver metastasis was recognized, though macroscopically, in 111 of 1988 surgical cases, the incidence being 5.6 per cent. The age distribution of these cases is shown in Table XXIII. The metastasis appeared to be a little more common in aged patients than in the young.

TABLE XXIII. Incidence of Liver Metastasis in 1988 Cases of Stomach Cancer, by Age

\begin{tabular}{c|c|cc}
\hline $\begin{array}{c}\text { Age } \\
\text { (years) }\end{array}$ & $\begin{array}{c}\text { Total no. } \\
\text { of cases }\end{array}$ & $\begin{array}{c}\text { No. of cases with } \\
\text { metastasis }\end{array}$ & Per cent \\
\hline$<40$ & 235 & 9 & 3.8 \\
$40-50$ & 446 & 17 & 3.8 \\
$50-60$ & 739 & 51 & 6.9 \\
$60 \leq$ & 568 & 34 & 6.0 \\
\hline Total & 1988 & 111 & 5.6
\end{tabular}

Palliative gastrectomy was performed in 37 of the 111 cases, composing 2.3 per cent of 1579 gastrectomy cases. In these cases, it was revealed that the frequency of liver metastasis was higher in tumors of Borrmann's Types I and II than in those of Types III and IV, and higher in carcinoma adenomatosum than in carcinoma solidum, as shown in Tables XXIV and XXV.

Ovarial metastasis: Metastasis to the ovarium has some characteristics in clinical and pathologic aspects and is known as Krukenberg's tumor. Although carcinoma of various organs can cause Krukenberg's metastasis, stomach cancer is the most frequent source as seen in literature (Table XXVI). The incidence of ovarial metastasis in autopsy cases of stomach cancer (females) was reported to be 21.4 per cent by Willis ${ }^{15)}$ and 10.3 per cent by Poscharissky ${ }^{16}$.

In the present series, ovarial metastasis of stomach cancer was found in 
TABLE XXIV. Relation between Gross Appearance of the Tumor and Liver Metastasis

\begin{tabular}{|c|c|c|c|}
\hline $\begin{array}{l}\text { Borrmann's } \\
\text { classification }\end{array}$ & $\begin{array}{l}\text { Total no. } \\
\text { of cases }\end{array}$ & $\begin{array}{l}\text { No. of cases } \\
\text { with metastasis }\end{array}$ & Per cent \\
\hline $\begin{array}{rr}\text { Type } & \text { I } \\
\text { II } \\
\text { III } \\
\text { IV }\end{array}$ & $\begin{array}{r}90 \\
799 \\
507 \\
183\end{array}$ & $\begin{array}{r}6 \\
23 \\
5 \\
3\end{array}$ & $\begin{array}{l}6.7 \\
2.9 \\
0.9 \\
1.9\end{array}$ \\
\hline
\end{tabular}

TABLE XXV. Relation between Histology of the

Tumor and Liver Metastasis

\begin{tabular}{l|c|cc}
\hline $\begin{array}{c}\text { Petersen-Colmers } \\
\text { classification }\end{array}$ & $\begin{array}{c}\text { Total no. } \\
\text { of cases }\end{array}$ & $\begin{array}{c}\text { No. of cases } \\
\text { with metastasis }\end{array}$ & Per cent \\
\hline Ca. adenomatosum & 704 & 24 & 3.4 \\
Ca. solidum & 823 & 11 & 1.3 \\
Mixed type & 52 & 2 & 3.8
\end{tabular}

TABLE XXVI. Source of Ovarial Metastasis, Review of Japanese Literature

\begin{tabular}{l|rc}
\hline $\begin{array}{c}\text { Location of primary } \\
\text { tumor }\end{array}$ & No. of cases & Per cent \\
\hline Stomach & 118 & 91.5 \\
Intestine & 4 & 3.1 \\
Breast & 3 & 2.3 \\
Urinary tract & 2 & 1.5 \\
Gallbladder & 1 & 0.8 \\
Liver & 1 & 0.8 \\
\hline \multicolumn{1}{c|}{ Total } & 129 & 100.0
\end{tabular}

eight of 595 female cases subjected to surgery for stomach cancer, the incidence being 1.3 per cent. The age ranged in these cases from 23 to 56 and four cases were under 40, agreeing with Willis' statement that young females of stomach cancer are more likely to develop ovarial metastasis than old ones since the metastasis prefers the actively functioning ovarium ${ }^{15}$.

The metastasis was bilateral in all but one of these cases. In two of the eight cases, the ovarium was involved after a lapse of time since gastrectomy for stomach cancer, while the ovarial tumors coexisted with carcinoma of the stomach in the remaining six cases. In the latter group, the diagnosis of stomach cancer with ovarial metastasis was established preoperatively in three cases while the ovarial tumors were recognized after laparotomy for stomach cancer in two cases. The remaining one case underwent surgery under the diagnosis of retroperitoneal tumor and the operation revealed ovarial tumors and small carcinoma of the stomach. 
Extirpation of ovarial tumors was performed in seven cases. In all but one of these cases, the tumor tissue showed the typical histologic pattern described by Krukenberg; the exceptional case was papillary adenocarcinoma. In six cases in which both resection of the stomach and extirpation of the ovariums were performed, the histologies of the primary tumors were carcinoma solidum diffusum in four cases and carcinoma adenomatosum simplex and the mixed type in one each of the others.

4. Stage of cancer progress

Although carcinoma of the stomach originates in the mucosal lining of the stomach and initially grows in the stomach wall, sooner or later it spreads beyond the stomach. Since the extragastric extension takes place through various routes, the extent of cancer progress may be evaluated from various points of view. In fact, the P.C. classification, L.M. classification and the presence or absence of distant metastasis are by themselves sure measures of cancer progress. However, a single scale of the extent of cancer spread may be desirable in studying the clinical aspects of stomach cancer at various stages of this disease. Such a scale used by the authors takes the peritoneal dissemination, lymph node involvement and remote metastasis as the major parameters.

The grading consists of four stages: Ia, Ib, II and III. Stage Ia refers to the condition in which carcinoma is entirely limited within the stomach wall, not showing serosal involvement (P.C. O), lymph node metastasis (L.M. O) nor metastasis to the distant organs. Stage $\mathrm{Ib}$ is the stadium in which carcinoma spreads out of the stomach but is still limited adjacent to the stomach; in this case there is either the peritoneal dissemination or lymph node metastasis of the first grade (P.C. I or L.M. I) or both, not showing metastasis to the remote organs. Stage II indicates moderately advanced yet still surgically controllable lesions, associated with either one or both of P.C. II and L.M. II but not showing distant organ metastasis. Stage III includes generalized lesions to which no surgical cure is expected, showing generalized peritoneal dissemination (P.C. III), involvement of remote lymph nodes (L.M. III) or metastasis to the remote organs.

The actual statistics in 1988 cases of the present series is shown in Table

TABLE XXVII. Stage of Cancer Progress in 1988 Surgical Cases of Stomach Cancer

\begin{tabular}{c|cc}
\hline Stage & No. of cases & Per cent \\
\hline Ia & 151 & 7.6 \\
Ib & 477 & 24.0 \\
II & 792 & 39.8 \\
III & 568 & 28.6 \\
\hline Total & 1988 & 100.0
\end{tabular}


XXVII. Those which were in Stages Ia, Ib or II, i.e. those indicating radical surgery, were 71.4 per cent of the total.

\section{References}

1) Segi, M. et al., Cancer Mortality for Selected Sites in 24 Countries (1950-1957), 1959 , Sendai.

2) Muto, M., Acta Un. int. Cancr., 1962, 18, 729.

3) Borrmann, R., Henke-Lubarsch's Hdb. spez. path. Anat. u. Histol., 1926, Bd. 4, Ht. $1,855$.

4) Petersen, W. \& Colmers, F., Beitr. klin. Chir., 1904, 43, 1.

5) Broders, A.C., Collected Papers Mayo Clinic, 1925, 17, 972.

6) Broders, A.C., ibid., 1925, 18, 1180.

7) Yamamura, F., Nippon Geka Gakkai Zasshi (Jap.), 1960, 61, 224.

8) Walters, W. et al., Carcinoma and Other Malignant Lesions of the Stomach, 1943, Philadelphia, 172.

9) Dochat, G.R. \& Gray, H.K., Collected Papers Mayo Clinic, 1943, 35, 22.

10) Imai, T., Obstet. and Gynec., 1960, 16, 296.

11) Mori, T., Nippon Geka Gakkai Zasshi (Jap.), 1962, 63, 732.

12) Majima, S. et al., To be published in this journal.

13) Sato, K., Nippon Geka Gakkai Zasshi (Jap.), 1958, 59, 263.

14) Maki, T., Majima, S., Yoshida, K. \& Takahashi, T., Tohoku J. Exper. Med., 1963, 79, 319 .

15) Willis, R.A., The Spread of Tumors in the Human Body, 1952, London, 133.

16) Poscharissky, T., Z. Krebsforsch., 1930, 31, 263. 